\title{
LOS CINCO SEÑORES RECIBIENDO LOS CORAZONES DE DONANTES CRIOLLOS E INDÍGENAS, UN LIENZO DE JERÓNIMO DE BOBADILLA EN CHILE
}

\author{
THE FIVE LORDS RECEIVE THE HEARTS OF CREOLE \\ AND INDIGENOUS DONORS, A CANVAS OF JERÓNIMO \\ DE BOBADILLA IN CHILE
}

\author{
ESCARDIEl GonZÁlez EstÉveZ \\ Universidad de Sevilla, España \\ escardielge@gmail.com
}

Se presenta ante la comunidad científica una nueva obra del poco conocido pintor sevillano Jerónimo de Bobadilla, firmada y fechada en 1684, y perteneciente al Museo del Carmen de Maipú en Santiago de Chile. Además de la importancia que significa engrosar el catálogo de uno de los desconocidos pintores sevillanos del Barroco, analizamos su original iconografía: el ofrecimiento de corazones por parte de donantes criollos e indígenas a los Cinco Señores, una sintaxis de la Sagrada Familia escasamente presente en España, pero muy habitual en el Nuevo Mundo.

Palabras clave: Jerónimo de Bobadilla, pintura barroca sevillana, Museo Carmen de Maipú, Iconografía, Cinco Señores.

We present to the scientific community a new canvas of the not-well known Sevillian painter Jerónimo de Bobadilla, signed and dated in 1684, and currently held at the Carmen de Maipú Museum in Santiago de Chile. In addition to enriching and enlarging the catalogue of one of the unknown Sevillian painters of the Baroque era, we will analyze the originality of its iconographical program: the offering of the hearts of creole and indigenous donors to the Five Lords, a syntax of the Holy Family, scarcely present in Spain, but not so unusual in the New World.

Keywords: Jerónimo de Bobadilla, Baroque Sevillian painting, Carmen of Maipú Museum, Iconography, Five Lords. 


\section{EL DESCONOCIDO JERÓNIMO DE BOBADILLA}

Jerónimo de Bobadilla integra esa amplia nómina de pintores secundarios que proliferaron en la Sevilla de la segunda mitad del XVII, debatiéndose entre las dos corrientes: las reminiscencias zurbaranescas y la nueva manera de Muri1lo. Su escaso catálogo no alcanza a sobrepasar la decena en la actualidad, con cuatro dibujos en museos extranjeros y cuatro óleos presentes en colecciones particulares malagueñas ${ }^{1}$, dados a conocer por Agustín Clavijo en su artículo de $1982^{2}$. A esto hemos podido añadir una Virgen con el niño durmiente (Figura 1) en las colecciones del Hermitage a través de un rastreo internaútico ${ }^{3}$. Por las noticias históricas ofrecidas desde Palomino sabemos, además, que hubo otras obras que, desgraciadamente, no han llegado a nuestros días, contabilizando un total de once. Así, el historiador cordobés relaciona seis lienzos de la Vida de Cristo para el platero Salvador de Baeza y, más tarde, Ceán dice que "sus obras están en los conventos y casas particulares"4 de Sevilla. En una almoneda celebrada en Madrid en 1789 se vendió una pintura de San Francisco de Paula con varios compañeros y angelitos ${ }^{5}$. M. del Carmen Heredia pudo recoger en sus pesquisas un Cristo atado a la columna en la puerta del Sagrario del altar de los Enciso y otras dos pinturas (sin especificar) en la Iglesia de san Antonio ${ }^{6}$. Y a ello hemos de sumar los dos lienzos que componían la serie malagueña de cinco, cuya pista se pierde

${ }^{1}$ Tres de estos formaban parte de una serie de cinco cuadros sobre la Vida de la Virgen, propiedad de D. Miguel Crooke, según una relación de 1851. Vid. CLAVIJO GARCÍA, Agustín: "Un zurbaranesco olvidado: el sevillano Jerónimo de Bobadilla (+ 1709)", Baetica. Estudios de Arte, Geografía e Historia, nº 6, 1982, pp. 49-82, p. 59.

${ }^{2}$ Ibidem. Se trata de la Adoración de los Magos (2), la Circuncisión y la Huida a Egipto, mientras los dibujos responden a un San José con el niño (Museo de Hamburgo), un San Lucas (colección particular londinense) y El hijo pródigo (colección Witt, Londres). Todos son reproducidos en el artículo, excepto este último. Sin embargo, en el catálogo de la reciente exposición celebrada en el Prado hasta el 8 de febrero de 2015, Dibujos españoles en la Kunsthalle de Hamburgo, Madrid, Museo del Prado, 2014, se le atribuye otro San José (este sentado sobre la hoja cuadriculada). Véanse para ambos dibujos homónimos las fichas de catálogo de HOFFMANN-SAMLAND, Jens, pp. 114-117.

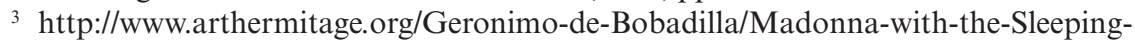
Infant-Christ.html. Consultado el 29-09-2014. El lienzo que se advierte firmado, se data en 1668, procedente de Cádiz en 1834. Es importante reseñar esto, ya que se trataría de la obra más temprana con fecha fidedigna. Hagamos notar que en este caso el nombre es escrito como Geronimo.

${ }^{4}$ CEÁN BERMÚDEZ, J. Agustín; Diccionario histórico de los más ilustres profesores de las Bellas Artes en España, Madrid, 1800, t. I, p. 151.

${ }^{5}$ CLAVIJO GARCÍA, Agustín: "Un zurbaranesco... op. cit., p. 54.

${ }^{6}$ HEREDIA, M. del Carmen: "Noticias sobre pintores sevillanos de comienzos del s. XVIII”, AA.VV. Homenaje al Prof. Dr. Hernández Díaz, Sevilla, 1982, p. 429. 
en un traslado ${ }^{7}$. El total de obras referenciadas ascendería a la veintena, entonces. Es evidente que la obra de Bobadilla fue mucho más amplia de lo que hoy conocemos. Acaso ese mejor dominio de ‘lo pequeño' que le asigna Palomino y que le valió, según su testimonio, encargos del propio Murillo, favorecieran una actividad centrada en el pequeño formato, por ende, de consumo más privado o personal; desgraciadamente, una tipología con menos perspectiva de conservación que las obras de gran formato para inmuebles eclesiásticos.

La difusión en el mundo académico de este lienzo que hoy se encuentra en Chile supone, por tanto, no solo la ampliación de tan exiguo catálogo, sino la esperanza de continuar descubriendo a otro artista de la pintura barroca sevillana, quizá de aquellos enfocados al tráfico con ultramar que siguiendo al maestro de Fuente de Cantos y por diversas circunstancias trabajaron ampliamente o casi en exclusiva para América, como Juan de Luzón ${ }^{8}$. Se van cumpliendo así los anhelos de A. Clavijo de que "vayan apareciendo más pinturas de su mano que contribuyan a afianzar mejor su personalidad dentro del barroco sevillano de la segunda mitad del s. XVII"9.

¿Fueron la producción enfocada al ámbito privado y/o al americano las razones del escaso conocimiento que sufre en la actualidad la figura de Jerónimo de Bobadilla? ¿O se debió a su impericia en un contexto genial de ardua competencia como el de los obradores sevillanos del s. XVII? La crítica, sin acritud pero sin concesiones, se ha pronunciado sobre la valoración del pintor de forma incontestable. Ceán sentenciaba que "no hizo todos los progresos que se esperaban de su afición" ${ }^{10}$ y un más connivente Palomino escribía que "por su camino fue de los célebres ingenios de la Pintura en esta facultad" "Ya en nuestros días, el profesor Valdivieso valoraba su "discreto talento artístico"12. Su participación en el hito de la Academia sevillana desde $1666^{13}$ pone de manifiesto, no obstante, una notoriedad cierta en el panorama crucial de aquellos años, al menos, a nivel institucional;

${ }^{7}$ CLAVIJO GARCÍA, Agustín: "Un zurbaranesco..., op. cit., pp. 59-60.

${ }^{8}$ KINKEAD, Duncan: "Juan de Luzón and the Sevillian Painting Trade with the New World in the Second Half of the Seventeenth Century", The Art Bulletin, 1984, vol. 66, $\mathrm{n}^{\circ} 2$, pp. 303-310.

${ }^{9}$ CLAVIJO GARCÍA, Agustín: "Un zurbaranesco..., op. cit., p. 57.

${ }^{10}$ CEÁN BERMUDÉZ, J. Agustín: Diccionario histórico..., op. cit., p. 151.

${ }^{11}$ PALOMINO Y VELASCO, Antonio: El Museo Pictórico y Escala Optica, Madrid, 1724 (edición de Aguilar, Madrid, 1974), pp. 998-999.

12 VALDIVIESO GONZÁLEZ, Enrique: Historia de la pintura sevillana, siglos XIII al $X X$, Sevilla, 2002, p. 243.

${ }^{13}$ CEÁN BERMUDÉZ, J. Agustín: Diccionario histórico... op. cit., p. 151. Vid. GARCÍA BAEZA, Antonio: Entre el obrador y la academia: La enseñanza de las artes en Sevilla durante la segunda mitad del Seiscientos. Sevilla, 2014, p. 268. 
y su nombramiento como uno de los alcaldes alamines de la pintura diez años después así lo acredita ${ }^{14}$.

En cualquier caso, esta escasez se ha traducido en una lógica, por otra parte, desatención. Más allá de las líneas dedicadas por el profesor Valdivieso en sus obras sobre la pintura barroca sevillana ${ }^{15}$, solo contamos con el artículo de Clavijo, quien, a través de su investigación pudo corregir los errores de la historiografía tradicional en torno a su filiación (no antequerana, sino de Sevilla) y las fechas de nacimiento y muerte, además de añadir otras de carácter biográfico.

\section{OTRO LIENZO SEVILLANO PARA AMÉRICA}

Los datos que se tienen en la actualidad sobre la trayectoria del lienzo no apuntan más que al anterior propietario que lo cedió al Museo del Carmen de Maipú: el arzobispo de Santiago de Chile Rafael Valentín Valdivieso (1804-1878). El desconocimiento de la procedencia anterior impide precisar el recorrido de la obra y sus circunstancias originales, pero el análisis de algunos de sus rasgos nos lleva a inclinarnos por la hipótesis de un encargo para América. La firma del pintor como 'Hispal.', (Figura 3) y especialmente en contraste con otras de sus firmas donde no aparece el gentilicio, indican un destino ajeno a la ciudad, como por ejemplo ocurre en los célebres lienzos pintados por Ignacio de Ries para la Catedral de Segovia, con el nombre de 'Sevilla' ${ }^{16}$. Sin duda, la marca de la ciudad, el gran estudio pictórico de España a nivel comercial, suponía un elemento de prestigio.

La presencia de la pareja indígena, así como de la negra, junto a los personajes criollos (Figura 4), un muy posible retrato de algún matrimonio acomodado en América, hacen pensar en un encargo hecho al pintor en Sevilla, o quizá desde el Nuevo Mundo para transportarlo allá. Si el destino concreto dentro del continente fue originalmente Chile o no, es algo que no podemos verificar, pero la presencia en Santiago desde el s. XIX y habida cuenta de la práctica inexistencia de un mercado de arte anticuario y de coleccionismo entonces, descartarían la posibilidad de un traslado por adquisición desde otro punto, posiblemente Lima. Aunque vicisitudes de diverso tipo podrían ser aducidas en contra, por ejemplo, el viaje con su propietario como parte de sus bienes, quizá de algún prelado.

Tanto las obras encargadas a los artistas sevillanos por patrones del Nuevo Mundo, como aquellas sin destino para la venta en los mercados americanos, y por ello mencionadas como 'mercaderías', eran dos tipos de comercio desarrollados por entonces que experimentaron un auge entre 1635-1655. Los obradores de

${ }^{14}$ HOFFMANN-SAMLAND, Jens: Dibujos... op. cit., p. 114.

15 VALDIVIESO GONZÁLEZ, Enrique: Historia de la pintura ... op. cit., y Pintura barroca sevillana, Sevilla, 2003, pp. 383-384.

${ }^{16}$ NAVARRETE PRIETO, Benito: Ignacio de Ries, Madrid, 2001. 
Zurbarán y del poco conocido Juan de Luzón, los dos estudios enfocados a la demanda americana, son testimonio de este fenómeno crucial para la historia del arte hispánico, aún por estudiar en muchas facetas ${ }^{17}$. No extrañará pues que un pintor de la Sevilla de entonces, formado con el maestro extremeño tuviera más pronto que tarde posibilidades de trabajar para América e, incluso, orientarse de forma exclusiva, como ocurriera con Luzón en la primera mitad del siglo.

Cabría entonces preguntarse si el escaso catálogo de Jerónimo de Bobadilla radica en la misma paradoja de una gran productividad y el casi completo anonimato que afectó al desconocido pintor sevillano Juan de Luzón y a otros como Juan López Carrasco, Miguel Güelles o Juan Fajardo, sacados a la palestra por Duncan Kinkead ${ }^{18}$. En los años que trabaja Bobadilla existen altibajos comerciales, los cuales son, según la opinión generalizada, la causa de la marcha de Zurbarán a Madrid, como señala Kinkead: "the importance of the American markets for the Sevillian artistic community actually increased during these fifty years" 19 . No obstante esto, hay un alza remarcable del volumen del mercado pictórico en la década de los noventa que, ciertamente, responde a la recuperación de la economía española en aquellos años, tras la caída de la década anterior ${ }^{20}$. Los datos son contundentes: al menos 7900 pinturas fueron enviadas al Nuevo Mundo desde $1672^{21}$. Nuestro lienzo, fuera enviado a una punto de la América marginal como Chile, o a la capital del virreinato peruano (eso sí, parece que siempre América del Sur, frente a la autosuficiencia de la producción en Nueva España) se incardina en esta coyuntura histórico-artística y comercial.

${ }^{17}$ Aunque se han dado pinceladas desde Diego Angulo y su generación, se ha hecho a tenor de las monografías de los grandes pintores (especialmente Zurbarán; véase NAVARRETE PRIETO, Benito y DELENDA, Odile: Zurbarán y su obrador: pinturas para el Nuevo Mundo, Madrid, Ayuntamiento, 1999), con apreciaciones tan lúcidas y valiosas como las de Juan Miguel Serrera o Miguel Morán, pero seguimos careciendo de trabajos concretos al respecto. Los estudios de Ducan Kinkead o de GARCÍA FUENTES, Lutgardo: El comercio español con América 1650-1700, Sevilla, 1980, esp. pp. 504-505, sean quizá las páginas más sustanciosas.

${ }^{18}$ KINDEAD, Duncan: "Juan de Luzón... op. cit., p. 303: "The artists who were associated almost exclusively with the export of paintings are now forgotten and their present anonymity has obscured the importance of the New World markets for the artistic economy of Seville".

${ }^{19}$ Ibídem, p. 307.

${ }^{20}$ Ibid. Desgraciadamente, "too little is known of the artistic economy of Seville in the decade to justify any additional commentary".

${ }^{21}$ Ibíd. 


\section{SEMPITERNO DILEMA ¿ZURBARÁN O MURILLO?}

Si atendemos al título del único estudio sobre el pintor, hemos de adscribirlo a la pléyade de los seguidores de Zurbarán, sin embargo, ya el propio autor habla de su murillismo, especialmente en los dibujos; como también lo hace Augusto Mayer, al calificarlo como "imitador muy débil de Murillo"22, a tenor del San José, que el mismo se encarga de publicar. Clavijo, por su parte, llega a advertir también una cierta aproximación a Cano y Bocanegra en algunos rasgos, como la tipología facial ovalada de la Virgen.

Aunque la cronología de los lienzos malagueños es estimada por el profesor Valdivieso entre 1650-55, resulta extraño que con solo quince años el pintor ya tuviera semejante madurez como para ejecutar series con tal autonomía. Esto si es que, como apunta el propio Valdivieso, nació en $1636^{23}$. Así que, a menos que naciera antes (y es probable; siempre con posterioridad a 1625, año del matrimonio de los progenitores) podríamos aducir un retraso. La única data fehaciente que se tenía hasta el momento era el San Lucas, de 1685, a lo cual viene a sumarse el lienzo que aquí presentamos, un año anterior (Figuras 2 y 3); además del perteneciente al Hermitage, fechado en 1668, y, por tanto, el primero (Figura 1). Es decir, que de considerarse zurbaranesco, sería, sin duda, uno retardatario. En el último tercio de la centuria, los aires del extremeño ya habían perdido predicamento en aras de Murillo. ¿Entonces cómo calificar a Bobadilla? Dejando a un lado exigencias taxonómicas, puede hablarse de un pintor con remembranzas zurbaranescas o un zurbaranismo atemperado que se imbrica con la nueva tendencia murillesca. Así puede advertirse en los lienzos malagueños (lástima que las imágenes sean en blanco y negro) y, desde luego, en el lienzo de Chile (Figura 2), donde el motivo central de la Virgen con el Niño se decanta absolutamente por la manera de $\mathrm{Mu}$ rillo, frente al espacio circundante. Este se halla marcado por un claroscuro de naturaleza tenebrista aprendido, sin duda, en el obrador de Zurbarán y unos tonos ocres que contrastan con el colorido e iluminación central. Pero en la pugna, parece vencer la tendencia murillesca, natural por otra parte, habida cuenta de lo avanzado de la data.

Tampoco podemos olvidar el ideal de belleza femenino de la Virgen, de fuerte impronta canesca, estableciendo paralelismos con los lienzos malagueños de la Circuncisión y la Adoración (Figura 5), y, sobre todo, del Hermitage (Figura 1), especialmente en la mirada baja que deja los párpados al descubierto y la boca

${ }^{22}$ MAYER, Augusto: "La colección de dibujos españoles en el Museo de Hamburgo", Boletín de la sociedad española de Excursiones, 1920, p. 132, lám. XIV.

${ }^{23}$ VALDIVIESO GONZÁLEZ, Enrique. Historia... op. cit., p. 243. El autor remite a Palomino y Clavijo, pero el primero no indica año y este último se limita a señalar cautamente que su nacimiento hubo de ser posterior a 1625, sin perder la esperanza de encontrar la partida de bautismo en los archivos parroquiales sevillanos, los cuales no pudo agotar. Vid. CLAVIJO GARCÍA, Agustín: "Un zurbaranesco... op. cit., p. 50. 
pequeña. Por otra parte, la solución de la aureola iluminativa también se presenta en la Huida a Egipto. Los tipos de san José y san Joaquín encuentran correspondencias importantes con las obras conocidas hasta entonces. La forma de resolver los personajes terrenales, tanto por lo que respecta a la retratística como a la plasmación de un tipo no habitual como el de los indígenas (Figura 4), reviste una mayor pericia de lo que hasta ahora se ha valorado; a lo que hemos de sumar una originalidad iconográfica inusitada, no solo para el repertorio del artista, sino de toda la pintura sevillana. La composición, determinada por el tema, tiene un evidente gusto italiano de cierto clasicismo al presentar un claro esquema de orden cerrado, valorando por encima de todo el espacio central donde se encuentra la Virgen con el Niño y a cuyo grupo se dirige la atención de todos los personajes de la escena.

\section{CORAZONES PARA LOS CINCO SEÑORES}

A la hora de identificar el poco habitual sujeto de este lienzo, y en lo que respecta a los personajes celestiales, nos hemos decantado por la etiqueta iconográfica de los 'Cinco Señores', desconocida en nuestro ámbito y sumamente extendida en el americano. Y lo hacemos así por ajustarse mejor a lo representado que la de 'Sagrada Parentela', la cual puede presentar multitud de aplicaciones, desde el Árbol de Jessé o de santa Emerenciana hasta el arquetipo aquí presente de los abuelos y padres de Jesús, pasando por las Tres Marías o los llamados 'retratos familiares'24. La denominación de 'Cinco Señores' parece originarse en 1729 con el texto de la religiosa novohispana María de la Santísima Trinidad, Devoción a los nombres de los cinco Señores Jesús, María, José, Joaquín y Ana $a^{25}$, adquiriendo fortuna en adelante. Esto no quiere decir que en la península ${ }^{26}$ no se utilizara este 'pentaesquema', pero parece mucho más habitual en ultramar ${ }^{27}$.

${ }^{24}$ MORENO CUADRO, Fernando: Iconografía de la Sagrada Familia, Córdoba, 1994.

${ }^{25}$ SANTÍSIMA TRINIDAD, María de la: Devoción a los nombres de los cinco Señores Jesus, Maria, Joseph, Joachim y Anna, México, Herederos de la Viuda de Francisco Rodríguez Lupercio, 1729.

${ }^{26}$ La Sagrada Parentela es un tema poco habitual en la iconografía peninsular, especialmente, en comparación con el desarrollo experimentado en latitudes nórdicas durante fines del s. XV. Mencionaremos la Santa Parentela de Herrera, el Viejo en el Museo de Bellas Artes de Bilbao (MORENO CUADRO, Fernando: Iconografía... op. cit., p. 37, fig. 25) o la Sagrada Parentela de Francisco Rizzi en colección privada madrileña (NAVARRETE PRIETO, Benito et al.: Fuentes y modelos de la pintura barroca madrileña, Madrid, 2009, p. 84, fig. 104). Ambos ejemplares son fechables hacia mediados del s. XVII, evidenciando el impulso otorgado en tal momento.

27 Citaremos algunos casos en que esta iconografía de los Cinco Señores interactúa con la de los Siete Arcángeles, estudiada en nuestra tesis doctoral: el Retablo de los 
De los cinco personajes, es, no obstante, Jesús infante quien acapara el protagonismo, situándose en el centro compositivo y con una luminosidad que contrasta con la atmósfera circundante. De hecho, es a él a quien realmente se dirige el ofrecimiento de los corazones, y así ocurre en la gran mayoría de los lienzos americanos, en los que, independientemente del esquema iconográfico (Sagrada Familia, san José,..) el Niño Jesús es el receptor de los corazones inflamados. Todos los personajes, religiosos y terrenales, aparecen supeditados a su presencia disponiéndose en torno, con una composición paréntesis que encierra la figura de la Virgen, no menos protagonista, como el cromatismo e iluminación sugieren. Es la única que no dirige su mirada al Niño Dios, sino a los indígenas y a la sirvienta negra que aparecen en el ángulo inferior izquierdo.

La pareja del lado derecho luce una indumentaria afecta a la moda del momento: él con calzones y chaqueta de mangas acuchilladas, con medias grises y cuello de puntas blanco, y ella con brocado en tonos celestes y ostentosos pendientes de lágrimas. Es marcado el contraste con la pareja indígena del lado frontero, ella en segundo plano y difícilmente perceptible por las sombras y la oxidación de los barnices. El personaje indígena aparece con la túnica habitual a rayas, la tilma en su hombro izquierdo y un tocado con cinta de plumas. Tras ellos, otra figura femenina de raza negra, con un pañuelo blanco sobre la cabeza, rasgo distintivo de esta etnia en las mujeres de la época. La interpretación pasa por la de un joven matrimonio criollo y parte de su servidumbre.

Todos aparecen arrodillados y sosteniendo un corazón en sus manos que entregan al Niño Jesús. El simbolismo del corazón, tan habitual en la literatura de todos los tiempos, fue más frecuente en lo religioso que en lo profano desde la Edad Media. Desde entonces, pero a partir, sobre todo, del Renacimiento, los santos o figuras simbólicas que sostienen sus corazones en las manos para ofrecerlos a Jesús, especialmente en su faceta de infante, o a la Virgen, se convirtieron en una imagen no poco frecuente hasta el punto de erigirse en un fórmula asen$\operatorname{tada}^{28}$. La base radicaba claramente en los textos bíblicos como el de Proverbios 23,26: "Dame, hijo mío, tu corazón". También pueden encontrarse variantes como santos que reciben corazones de Dios, o intercambio de corazones entre ambos (como la leyenda de Santa Catalina de Siena, representada en la órbita

Arcángeles en la capilla homónima de la Catedral de México, obra contratada en 1713 con el retablista Manuel de Nava, y en el plano pictórico el lienzo de Francisco Antonio Vallejo que se encuentra en la sacristía del Antiguo Colegio de san Ildefonso de la misma ciudad (1761) o el lienzo dieciochesco anónimo que atesora el Museo Nacional de Virreinato en Tepotzotlán.

${ }^{28}$ KNIPPING, John B.: Iconography of the Counter Reformation in the Netherlands: heaven on earth, Nieuwkoop-Leiden, B. de Graaf, 1974, vol. I, pp. 98-100. El autor documenta este gesto desde comienzos del s. XVI en la pintura holandesa como el lienzo de Joos van Cleve, Beato Enrique Suso ofreciendo su corazón a Jesús, 1530, Louvre. 
sevillana por Sebastián de Llanos Valdés en un lienzo poco anterior al aquí tratado, ca. $1670^{29}$ ). Pero con lo que el motivo-corazón se popularizó fue con las series de emblemas que expresan las diferentes fases en la relación del hombre con Cristo, o más generalmente con los rasgos de la vida cristiana, como la Schola cordis de Van Haeften, grabada por Boece a Bolswert por citar solo uno ${ }^{30}$. En el ámbito hispánico fue el jesuita Vega quien consolidó el simbolismo del corazón con una serie de emblemas de gran difusión, aunque escaso atractivo plástico ${ }^{31}$.

En este proceso, que tiene su periodo culminante en el s. XVII, siglo de nuestro lienzo, es crucial el papel de la orden carmelita, especialmente de su fundadora santa Teresa, que junto con san Felipe Neri o san Francisco Xavier conforma la nómina de los llamados 'santos del corazón'. La abulense, que consideraba el ardiente amor más necesario que la discusión teológica para llegar a Dios, inicia esta poderosa corriente espiritual que en el s. XVII acuña la filosofía del corazón en búsqueda de Dios (la filosofía "sensible au coeur") como Blais Pascal se encarga de resumir: no es el intelecto por lo que Dios puede ser sentido, sino por el corazón $^{32}$. En la segunda mitad de la centuria, Margarita María de Alacoque despertó con sus visiones una devoción al Corazón de Jesús, en esta línea más afectiva que teológica.

Tampoco ha de olvidarse la contribución de la espiritualidad jesuita o la dominante del conventualismo femenino. Todos estos ingredientes han instado a tachar de sentimentaloide el arte del s. XVII (creemos más justo quedarnos en una preponderancia al sentimiento); y la proliferación de este simbolismo del corazón ha sido utilizada como una de sus imágenes más descriptivas.

En América volvemos a encontrar este modelo en el contexto neogranadino, con una cronología más temprana que el lienzo de Bobadilla, pues la Virgen de los corazones $^{33}$ de Bogotá, (Figura 6) se fecha a mediados del s. XVII. Los Cinco Señores, con una composición no alejada del lienzo chileno, ofrecen corazones ardientes al Niño, junto al pontífice Inocencio X y a fray Cristóbal de Torres, arzobispo de Bogotá entonces, mientras varios caballeros, uno con el hábito de Santiago, don Francisco Fernández de Acuña, asisten en un segundo plano. La estancia del teólogo dominico como docente en Sevilla (predicador real de palacio), antes de su nombramiento como arzobispo de Santa Fe en 1634, lo pone en

${ }^{29}$ El lienzo se encuentra en una colección particular de Jerez de la Frontera. Vid. VALDIVIESO GONZÁLEZ, Enrique: Pintura barroca ... op. cit., lám. 293.

${ }^{30}$ Ibídem, pp. 99-103.

${ }^{31}$ SEBASTIÁN, Santiago: Contrarreforma y barroco. Lecturas iconográficas e iconológicas, Madrid, 1989, p. 326.

${ }^{32}$ KNIPPING, John B.: Iconography... op. cit., p. 96. SEBASTIÁN, Santiago: Contrarreforma... op. cit., pp. 322-327.

${ }^{33}$ BORJA GÓMEZ, Jaime Humberto: Arte Sacro, 450 años, Arquidiócesis de Bogotá, Bogotá, 2012, p. 80, imagen 60 . 
relación con el lienzo de Bobadilla, aunque no podamos aventurar la naturaleza de tal relación.

También pueden rastrearse donantes de corazones para con diversos santos, como en el lienzo ecuatoriano del matrimonio criollo de los marqueses de Miraflores, quienes ofrecen sus corazones ardientes a un san José carpintero con el niño ${ }^{34}$. Sin embargo, fue más afortunado el esquema en el que los donantes de corazones correspondían a santos, especialmente, a aquellos relacionados con el culto: como santa Teresa, santa Margarita Alacoque, san Ignacio y, más repetidamente, san Francisco Xavier. Ambos santos jesuitas, junto con la santa francesa aparecen sosteniendo sus corazones inflamados bajo la Sagrada Familia en un lienzo anónimo que se encuentra en Argentina (Figura 7), mientras que el último vuelve a aparecer ante un Cristo cargando la cruz y ayudado por tres dominicos peruanos, entre ellos, Martín de Porres en un lienzo de Manuel de Córdova (Museo de la Moneda, Potosí, Bolivia). Es el único caso donde la figura de Jesús no aparece en su tipología de infante.

Volviendo al lienzo, la presentación de todos los personajes en la misma actitud pone de relieve su equidad ante Dios, independientemente del factor étnico o la indumentaria. Sin embargo, podemos advertir una cierta actitud de protección sobre los no occidentales, como son las manos de san Joaquín presentándolos ante el Niño o la de la Virgen que, como indica su mirada, dirige su atención a los indígenas. Poco acostumbrado resulta ver a donantes de etnias y estratos socioeconómicos distintos presentados al mismo nivel y sin rasgos jerarquizadores. $\mathrm{Si}$ interpretamos el lienzo como un retrato del matrimonio criollo con parte de su servidumbre, tanto más extraño resulta esta paridad. Pero, ¿podría entenderse a los personajes terrenales como arquetipos de los distintos estratos existentes en el conglomerado social americano? Esta lectura parece encajar mejor con la disposición igualitaria y quizá su comitente así lo encargase expresamente, pero los rasgos individualizados del matrimonio criollo hacen decantarse por un retrato. Ello contrasta más si cabe, con el aspecto convencionalizado de los otros personajes, especialmente de los indígenas, que raramente solían llevar un tocado plumario en la cabeza. Posiblemente, Bobadilla, no había alcanzado a ver ninguno en la Sevilla del momento, valiéndose para este lienzo de la espuria y tendenciosa imagen difundida en los grabados desde hacía tiempo ${ }^{35}$.

Fecha de recepción: 30 de septiembre de 2014

Fecha de aceptación: 28 de noviembre de 2014

\footnotetext{
${ }^{34}$ Agradezco la información y algunas de las imágenes americanas a mi compañera, la $\mathrm{Ph}$. D. Cristina Cabrera Lema de la Universidad de Giessen, Alemania.

${ }^{35}$ SANFUENTES, Olaya: Develando el Nuevo Mundo. Imágenes de un proceso, Santiago de Chile, 2009.
} 


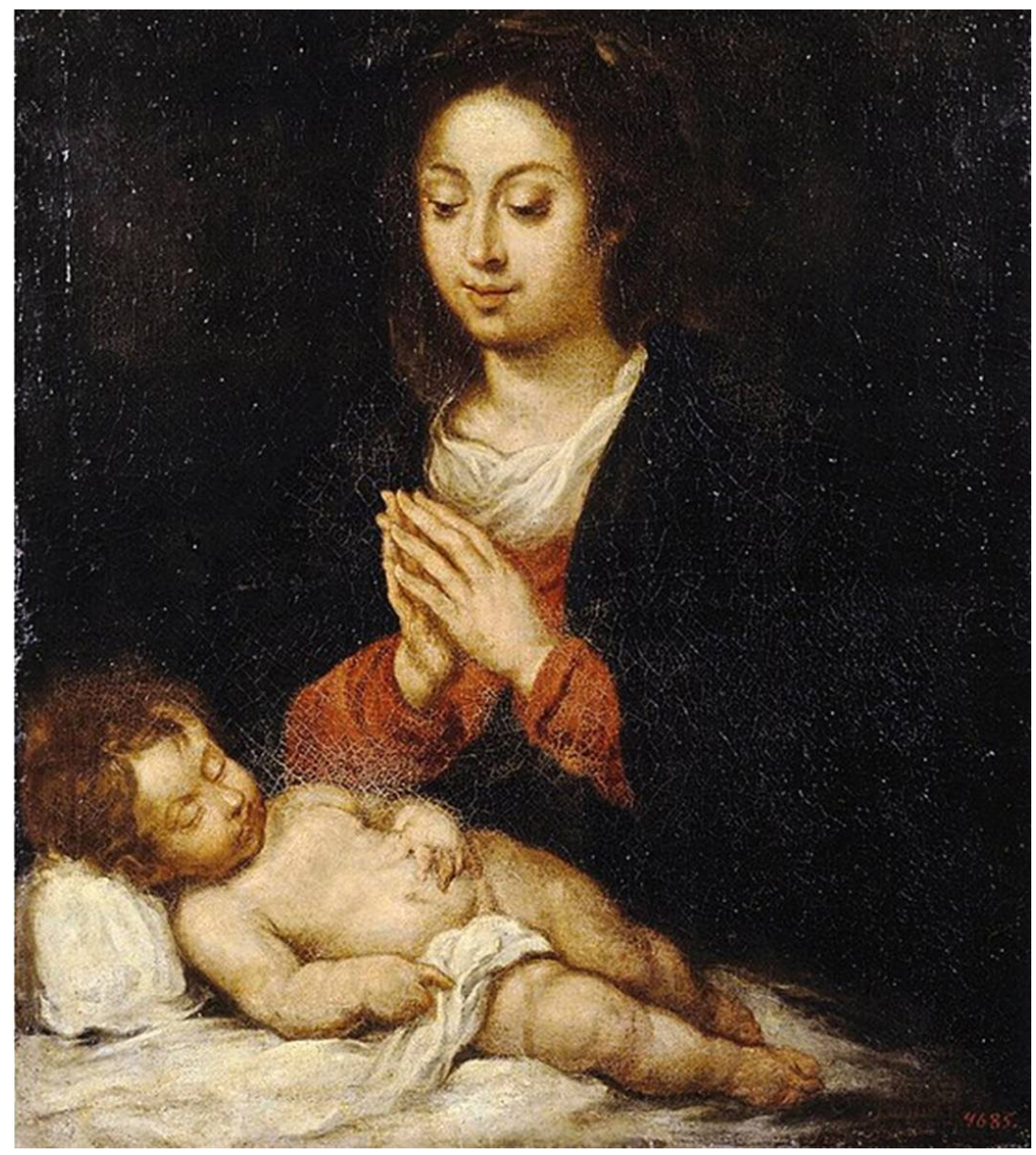

Figura 1. Virgen con el niño durmiente, Jerónimo de Bobadilla, 1668, Museo del Hermitage, San Petersburgo. 


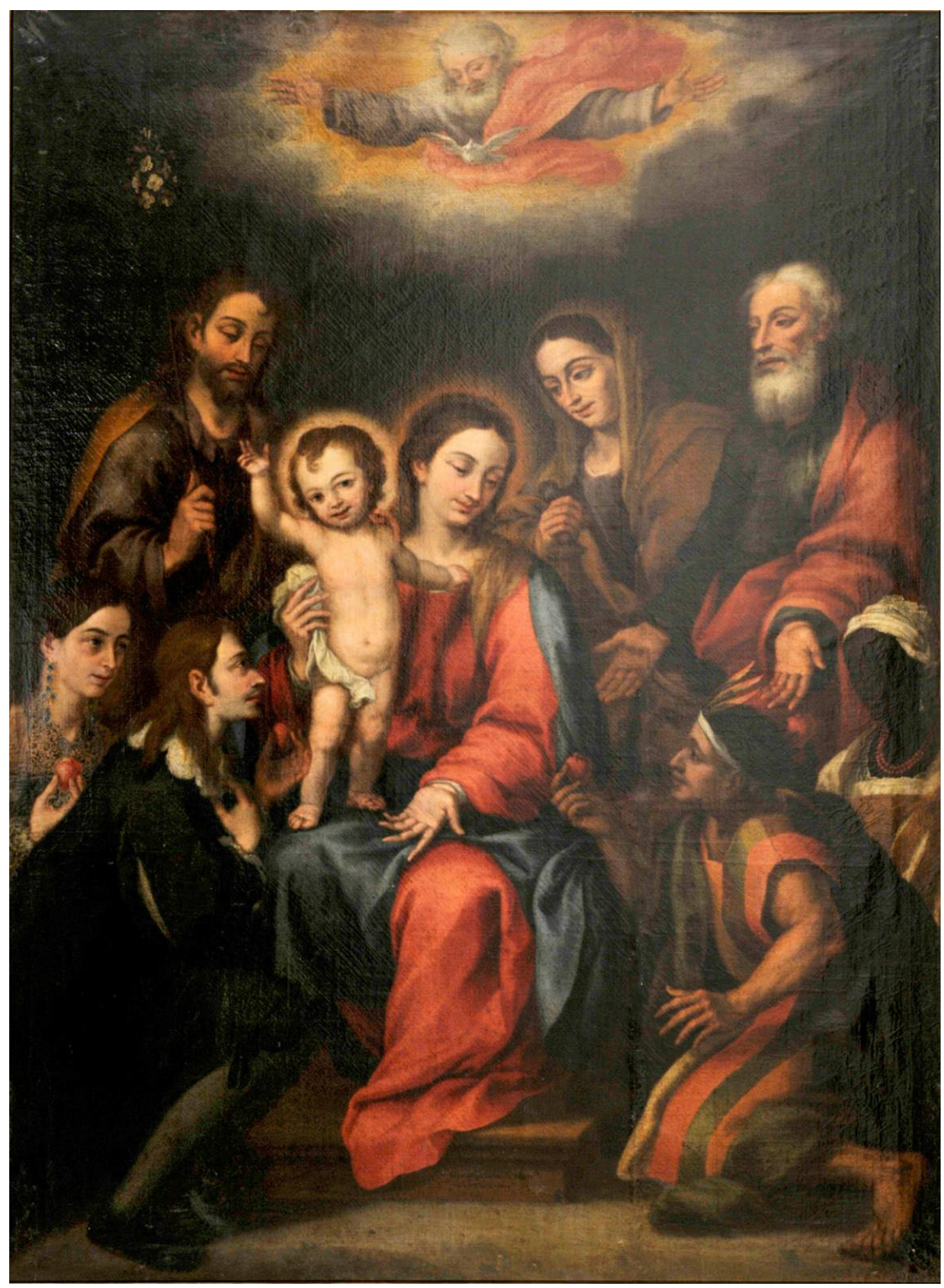

Figura 2. Los Cinco Señores recibiendo los corazones de donantes criollos e indígenas, Jerónimo de Bobadilla, 1684, Museo del Carmen de Maipú, Santiago de Chile. 


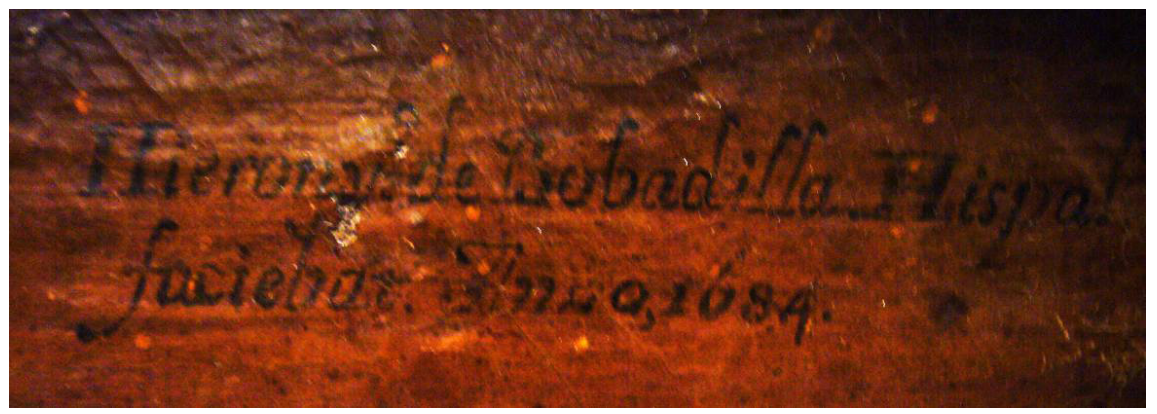

Figura 3. Los Cinco Señores recibiendo los corazones de donantes criollos e indígenas, Jerónimo de Bobadilla, 1684, Museo del Carmen de Maipú, Santiago de Chile. Detalle de la firma.

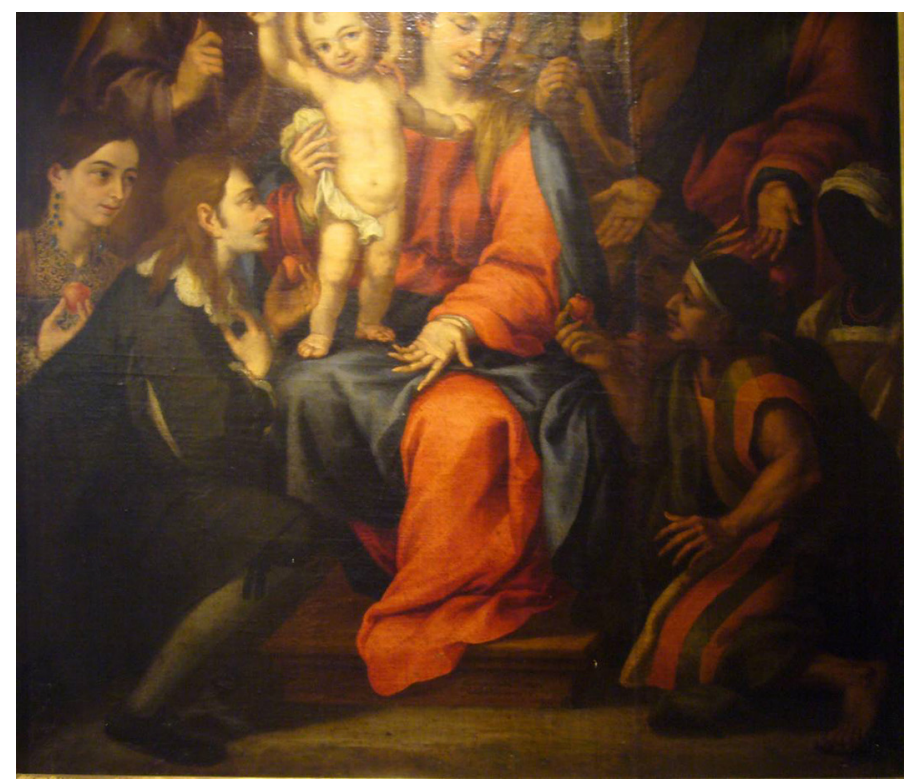

Figura 4 Los Cinco Señores recibiendo los corazones de donantes criollos e indígenas, Jerónimo de Bobadilla, 1684, Museo del Carmen de Maipú, Santiago de Chile. Detalle de los donantes. 


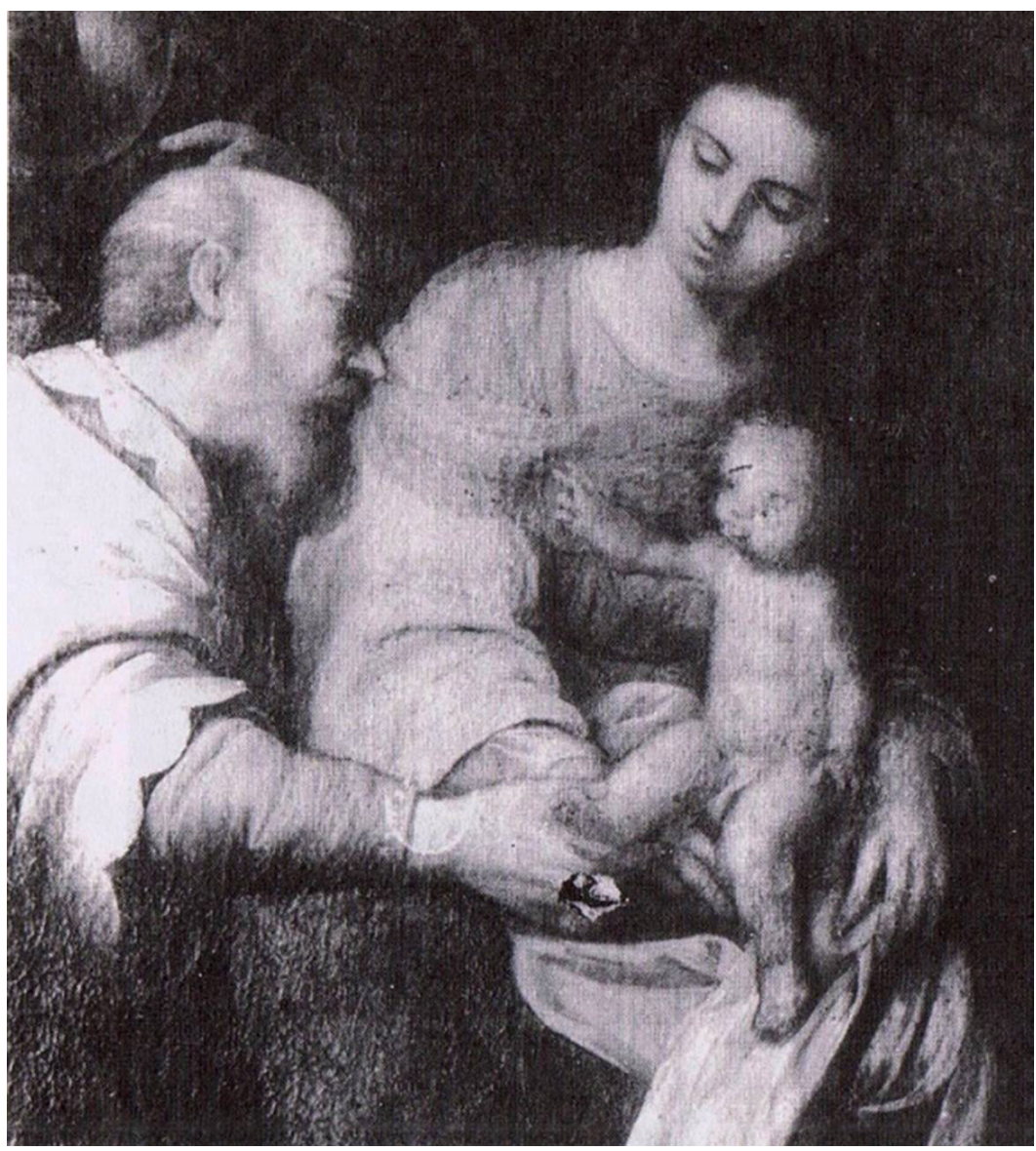

Figura 5. Adoración de los Magos, Jerónimo de Bobadilla, ca. 1660, Colección particular, Málaga. 


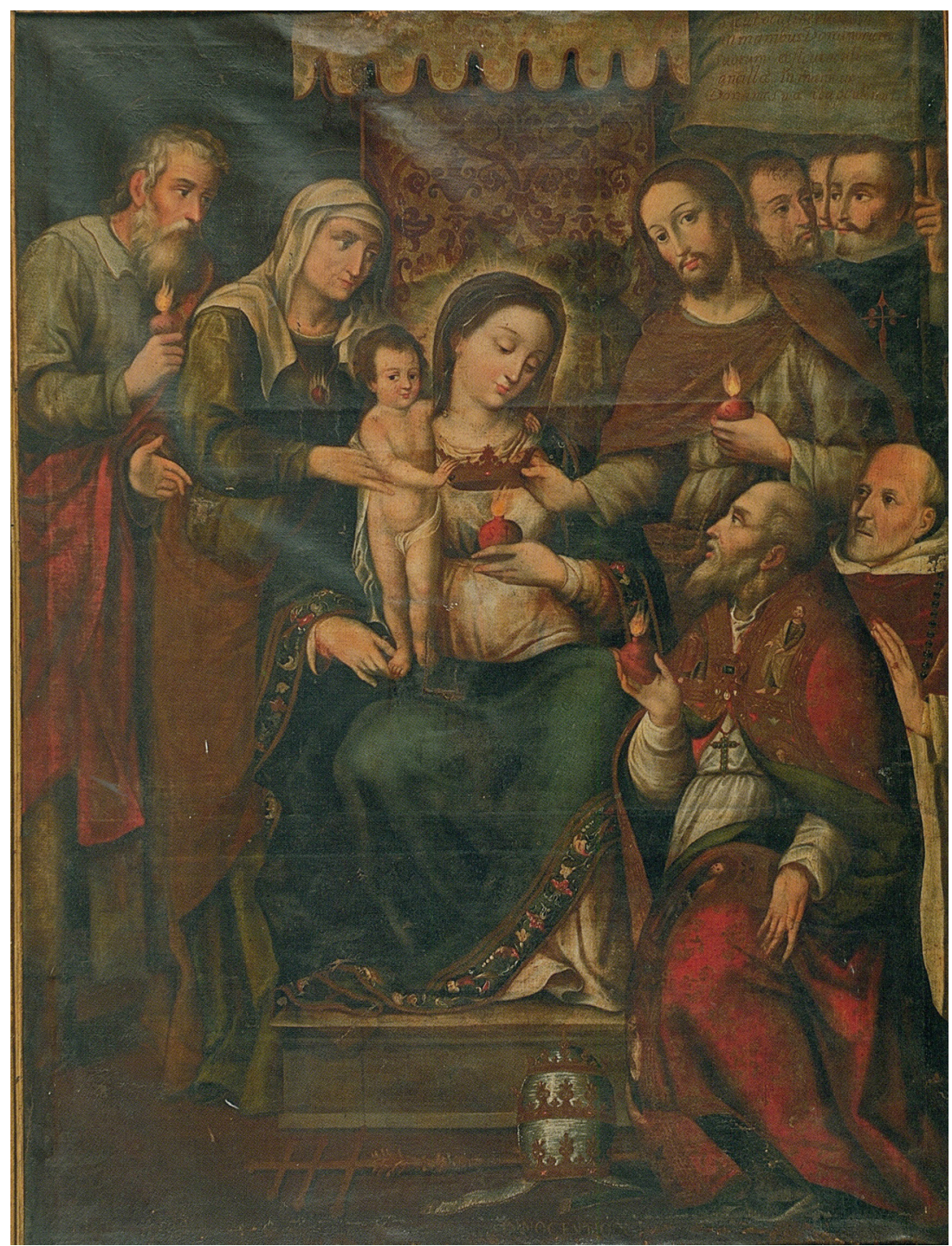

Figura 6. La Virgen de los Corazones, atribuido a Baltasar de Vargas Figueroa o a Gregorio Vázquez de Arce, mediados del s. XVII, Iglesia de Nuestra Señora de las Aguas, Bogotá. 


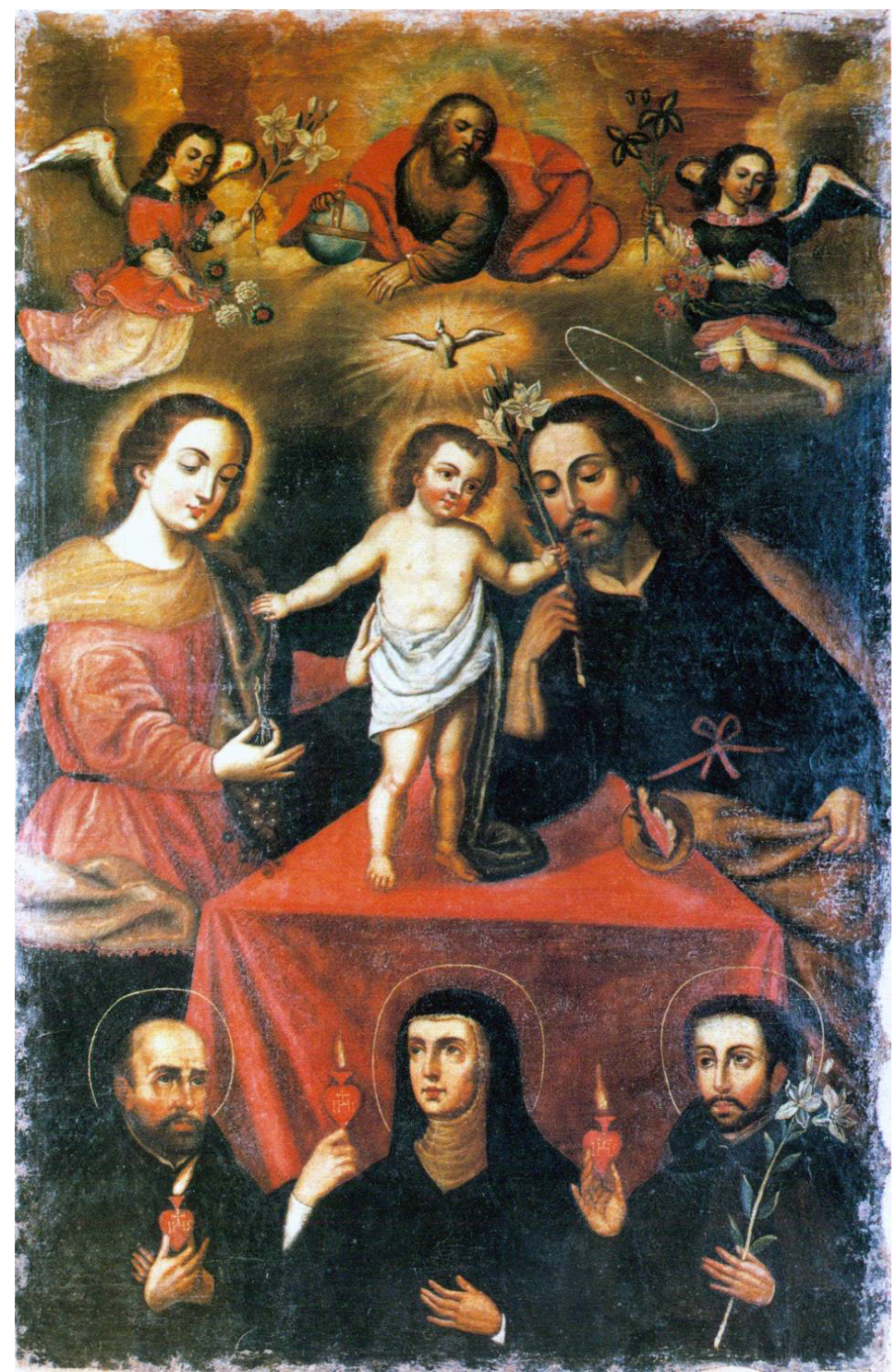

Figura 7. La Sagrada Familia recibe los corazones de san Ignacio, santa Margarita María Alacoque y san Antonio de Padua, Anónimo, segunda mitad del s. XVIII, Monasterio de Santa Catalina, Córdoba, Argentina. 